\title{
TRIAGEM VIRTUAL PARA IDENTIFICAÇÃO DE INIBIDORES DA GLUTATIONA S
} -TRANSFERASES.

\author{
Kryzia Santana da Silva ${ }^{1}$; Manoelito Coelho dos Santos Júnior ${ }^{2}$ \\ 1. Bolsista PROBIC/CNPq, Graduando em Farmácia, Universidade Estadual de Feira de Santana, e-mail: \\ kryziasantana@gmail.com \\ 2. Orientador, Departamento de saúde, Universidade Estadual de Feira de Santana, e-mail: \\ mc2500@gmail.com
}

PALAVRAS-CHAVE: Ocotea; carrapato; glutationa S-transferases.

\section{INTRODUÇÃO}

A bovinocultura é conhecida como um dos principais destaques do agronegócio brasileiro no cenário mundial, e tem sua produtividade comprometida por uma espécie de carrapato conhecida como Rhipicephalus (Boophilus) microplus (FONSECA, 2012; GRISI et al., 2014; BRASIL, 2015; RECK JUNIOR et al., 2009). As investigações com produtos de origem vegetal são métodos alternativos a principal medida de controle utilizada na pecuária bovina atualmente, que é o uso de acaricidas sintéticos nos animais infectados (BROGLIOMICHELETTI et al., 2009; FERREIRA, 2002; FURLONG, 2007).

Neste cenário, uma das metodologias que pode ser empregada para otimizar a identificação de potenciais moléculas para o controle do Rhipicephalus (Boophilus)microplus é a realização de técnicas virtuais com o intuito de encontrar potenciais inibidores para alvos estabelecidos.

A glutationa S-transferases (GST) é uma família de enzimas responsável pela conjugação de xenobióticoseletrofílicos, reduzindo sua toxicidade e permitindo que o sistema de transporte elimine estes conjugados para o meio extracelular (ENAYATI; RANSON e HEMINGWAY, 2005). Essas enzimas também têm funções de proteção contra estresse oxidativo e o transporte intracelular de proteínas. Maior atividade da GST foi associada com a resistência de carrapatos $R .(B$.$) annulatus a acaricidas da classe dos piretroides (ZIPOUR et al., 2016).$

Este estudo contribuirá para a descoberta de novos princípios ativos para o controle de ectoparasitoses de bovinos. Inicialmente será construído um banco de moléculas oriundas de plantas do gênero Ocotea, em seguidas a afinidade das mesmas será avaliada por acoplamento molecular frente á GST. Espera-se com isso contribuir para o controle do Rhipicephalus (Boophilus) microplus e com isso com a bovinocultura.

\section{MATERIAL E MÉTODOS OU METODOLOGIA}

A enzima Glutationa S-transferase de Rhipicephalus (Boophilus) microplus (RmGST) não possui estrutura 3D elucidada, com isso será utilizado a técnica de modelagem comparativa para construção in silico de um modelo estrutural que será utilizado para os ensaios de triagem virtual baseada em afinidade molecular. A sequência primária da RmGST será obtida do banco UniProt. A sequência obtida será submetida ao PSI-BLAST (ALTSCHUL et al, 1997) contra as do banco de dados Protein Data Bank (PDB), onde serão selecionadas estruturas de proteínas conhecidas para molde(s), que apresentem identidade sequencial igual ou superior a $45 \%$ (GOLDSMITH-FISCHMAN, HONIG, 2003). Os moldes encontrados e a sequencia alvo serão alinhadas pelo servidor T-coffee (NOTREDAME et al., 2000).

A predição da estrutura $3 \mathrm{D}$ da região conservada do receptor será feita por modelagem comparativa, restrição de corpos rígidos na plataforma online SWISSMODEL através do método automático de construção (BIASINI et al., 2014). O refinamento do modelo construído será realizado no programa SANDER presente no pacote AMBER 12, que emprega um método de mecânica molecular (MM) com o campo de força ff03 para otimização de estruturas macromoleculares (CASE et al., 2008). A neutralização do sistema será realizada pelo programa tLeaP, também do pacote AMBER 12 (CASE et al., 2008). O modelo gerado será solvatado no programa tLeap, utilizando modelo de solvatação SPCBOX com espaçamento de $9.0 \AA$. O limite periódico será determinado por uma otimização inicial de 3000 ciclos (1500 com SteepestDescent [SD] e 5000 com Gradiente Conjugado [GC]), apenas o solvente possuirá liberdade espacial, a proteína será mantida restrita espacialmente por uma força de restrição de $500 \mathrm{kcal} / \mathrm{mol}$. Esta etapa será implementada no programa SANDER. Ao findar esta etapa, será 
realizada outra otimização, mas sem a restrição espacial, sendo 10.000 com SD e 5.000 com GC (CASE et al., 2008).

A validação estérica e energética do modelo construído será realizada nos programas PROCHECK (LASKOWSKI et al., 1993) e ANOLEA (MELO et al., 1997), respectivamente. A etapa subsequente envolve a utilização do modelo construído para identificação de inibidores da RmGST por acoplamento molecular. Para tal fim, primeiramente será realizada uma seleção para compor o conjunto de dados de pequenas moléculas que serão utilizadas no processo. $\mathrm{O}$ conjunto de ligantes que será utilizado no estudo será obtido do $\mathrm{ZINC}^{15}$, um dos maiores acervos mundiais de estruturas químicas para estudos de pesquisa e desenvolvimento de novos fármacos. (IRWIN J. J. et al., 2015). A base de dados utilizada no $\mathrm{ZINC}^{15}$ será a de produtos naturais a qual é composta por cerca de 180 mil compostos.

Para os estudos de acoplamento molecular será utilizado o programa DOCK 6.5 e acessórios, que aplica o método sistêmico, com função de pontuação baseados no campo de força de mecânica molecular (LANG et al., 2015). A delimitação do espaço de acoplamento molecular será feita inicialmente com o cálculo da superfície molecular de acesso ao solvente do receptor gerada pelo programa acessório DMS. A partir do DMS será construída a imagem negativa da superfície molecular do sítio ortostérico (região de ligação do ligante cristalográfico) pelos programas SPHGEN e SPHERE_SELECTOR (KUNTZ et al., 1982). As propriedades moleculares para a região de acoplamento molecular serão calculadas pelo programa GRID em sua configuração padrão (MENG; SHOICHET; KUNTZ, 1992). Para pontuação das moléculas será utilizada a função GridScore. As moléculas serão ordenadas por energia de afinidade e comparadas com inibidores clássicos de cada alvo. As moléculas serão ranqueadas por número, aquelas com melhores resultados serão analisadas de acordo com seu padrão de ligação com a enzima. Assim, a análise das interações intermoleculares, será realizada no programa PLIP (SALENTIN, 2015).

\section{RESULTADOS E/OU DISCUSSÃO}

Para a obtenção da sequência proteica alvo do parasito, realizou-se uma busca no NCBI (National Center for Biotechnology Information) da sequência da enzima glutationa Stransferase do organismo Rhipicephalus Boophilus (RmGST), as 12 encontradas foram alinhadas no programa T-COFFEE selecionando a ADQ0106.1 como a mais representativa, sendo em seguida submetida para consulta realizada no banco de dados Protein Data Bank (PDB) para tanto, a consulta foi e contou com o auxílio do algoritmo PSI-BLAST. Com isto, selecionou-se como molde a cadeia A da estrutura cristalina da GST de Rattus norvegicusque (PDB: 6GST) com identidade sequencial de 90\%, cobertura de $89 \%$ da RmGST, que apresentou a melhor resolução cristalográfica (2,2 Angstroms) e que possuia ligante complexado em seu sítio ativo..

O modelo construído no MODELLER da enzima glutationa S-transferase escolhido foi o com menor índice de proteínas discretas (DOPE) de -0,65. As sobreposições dos modelos selecionados em comparação com os modelos (6GST) no carrapato apresentaram o RMSD de $1.129 \AA$ A representado na figura 1 .

Figura 1 - Sobreposição do modelo RmGST (amarelo) e do molde PDB-6GST (azul), RMSD: $1.129 \AA$.

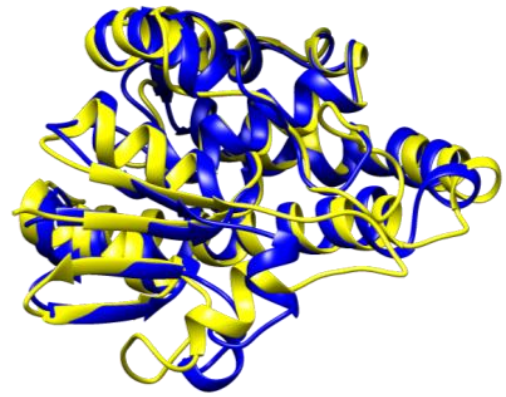

FONTE: AUTORA, 2018. 
Para validar o modelo analisou-se o gráfico Ramachandran onde no modelo 94,4\% dos resíduos se encontram em regiões favoráveis, $5,1 \%$ em regiões permitidas, $0,5 \%$ em regiões generosamente permitidas e apenas um resíduo $(0,3 \%)$ em regiões não permitidas. Indicando alta qualidade estérica no modelo. Os resultados do ANOLEA exibiram a predominância dos valores de energia negativa (17,94 \% dos aminoácidos), sugerindo uma boa qualidade energética do modelo. As funções de pontuação QMEAN6 e ZSCORE foi estimado em -0,25, menor que 1 podendo ser considerada de alta qualidade.

Para refinar e avaliar a estabilidade estrutural do modelo comparativo de RmGST, foram realizadas etapas de minimização de energia e uma simulação por dinâmica molecular (DM) com duração de 20ns. Ao analisar a trajetória foi observado que o modelo RmAGST atingiu a estabilidade após $10 \mathrm{~ns}$ de simulação, onde o valor médio do RMSD correspondeu a 38,5 \pm 0,30 A. Os seguintes resíduos apresentaram valores de RMSF proeminentes em relação aos demais (> 2,5 Â): Pro1, Tyr39, Glu121, Leu173. Esses resíduos foram localizados em regiões de alça, que permitem maior flexibilidade. O raio de giro também foi analisado, nele foi possível inferir que a RmGST se manteve compactada durante toda trajetória.

Para realização dos estudos de acoplamento molecular foram selecionados 9 moléculas isoladas do gênero Ocotea. No programa MarvinSketch (versão 17.8), as estruturas foram analisadas e desenhadas conforme a sua protonação no $\mathrm{pH}=7,5$. Em seguida, foram adicionados aos ligantes os átomos de hidrogênios e cargas Gasteiger utilizando o programa UFSC Chimera 1.9.8. Os resultados do acoplamento molecular entre as moléculas e a cadeia A da estrutura (6GST) utilizada como molde demonstram que o composto Quercetin 3-O- $\beta$-Dglucopyranoside apresentou o melhor valor do Gridscore $(-41.02 \mathrm{kcal} / \mathrm{mol})$ em comparação com todos os outros compostos, resultado semelhante obtido com o acoplamento com o modelo construído. A molécula de Quercetin 3-O- $\beta$-D-glucopyranoside é um flavonoide que foi isolado no estudo de Costa et al (2014) apartir da investigação fitoquímica da planta da espécie Ocotea notata do Parque Nacional Restinga Jurubatiba, Macaé, RJ, Brasil, onde observou-se propriedades antimicrobianas. As interações intermoleculares entre o composto e o molde comparativo comuns as com o molde são ligações de hidrogênio.

\section{CONSIDERAÇÕES FINAIS}

Os estudos de triagem virtual podem ser utilizados para seleção inicial de ligantes, evitando-se testar moléculas sem potencial inibidor frente a um determinado alvo. Desta forma, o emprego de triagens virtuais nas etapas iniciais de trabalhos para a descoberta de fármacos tem mostrado bons resultados.

Nesse trabalho foi desenvolvido um modelo 3D da Glutationa $\mathrm{S}$ transferase do $R$. microopluscom adequada qualidade estérica e energética, e com boa capacidade preditiva para a identificação de novas substâncias com potencial efeito carrapaticida sobre a $R m G S T$. Dentre os moléculas testadas a Quercetin3-O- $\beta$-D-glucopyranosideapresentou maior afinidade frente a RmGST comprovando a qualidade do modelo gerado.

\section{REFERÊNCIAS}

ALTSCHUL, S. F. E. A. Gapped BLAST and PSI-BLAST: a new generation of protein database search programs. Nucleic Acids Res., 25, 1997.

BIASINI, M.; BIENERT, S.; WATERHOUSE, A.; ARNOLD, K; STUDER, G.; SCHMIDT, T.; KIEFER, F.; CASSARINO, T. G.; BERTONI, M.; BORDOLI, L.; SCHWEDE, T. SWISSMODEL:modellingproteintertiaryandquaternarystructureusingevolutionaryinformationNucleicA cidsResearch. v. 42, n.1, p. 252-258, 2014.

BRASIL. Ministério da Agricultura. Bovinos e bubalinos. Disponível em: $<$ http://www.agricultura.gov.br/portal/page/portal/InternetMAPA/paginainicial/animal/espec ies. Acesso em 05/10/2017.

BROGLIO-MICHELETTI, S. M. F. et al. Extratos de plantas no controle de Rhipicephalus (Boophilus) microplus (Canestrini, 1887) (Acari: Ixodidae) em laboratório. RevistaBrasileira de Parasitologia Veterinaria, v. 18, n. 4, p. 44-48, 2009.

CASE, D. A. E. A. et AMBER 12, San Francisco, 2008. 
ENAYATI, A.A.; RANSON, H.; HEMINGWAY, J. Insect glutathione transferases and insecticide resistance.Insect Molecular Biology, v.14, n.1, p.3-8, 2005.

FERREIRA. C.A.S. Clonagem, caracterização e expressão de cDNAs similares a calreticulina e paramiosina isolados de glândula salivar do carrapato Boophilusmicroplus (Canestrini, 1887). Tese de doutorado. Universidade Federal do RioGrande do Sul Programa de Pós-Graduação em Ciências Biológicas: Bioquímica. 2002.

FONSECA, L.A. Impactos econômicos causados pela infestação de carrapatos em bovinos e o controle estratégico. ProCampo, Linhares, 39a edição (Ago/Set 2012). Disponível em < http://www.revistaprocampo.com.br/ver-noticia/68> Acesso em: 06/10/2017.

FURLONG, J. MARTINS, J.R, PRATA,M.C.A. O carrapato dos bovinos e a resistência: temos o que comemorar? A Hora Veterinária - Ano 27, no 159, setembro/outubro/2007. Ministério da Agricultura. Bovinos e bubalinos. Disponível em:<http://www.agricultura.gov.br/portal/page/portal/Internet-MAPA/paginainicial/an ima 1/especies $>$. Acesso em 06/10/2017.

GOLDSMITH-FISCHMAN, S.; HONIG, B. Strutural genomics: Computational methods for struture and analysis. Protein Science, 12, 2003.

GRISI, L. et al. Reassessmentofthepotentialeconomicimpactofcattle parasites in Brazil. Braz. J. Vet. Parasitol., v. 23, n. 2, p. 150-156, 2014.

KUNTZ, I.D. et al. A geometric approach tomacromolecule-ligandinteractions.

Journal Molecular Biological, v.161, p. 269-288, 1982.

LANG, P.T. et al. DOCK 6.7 UsersManual.RegentsoftheUniversityofCalifornia,

2015.

LASKOWSKI, R. A.; MACARTHUR, M. W.; MOSS D. S.; THORNTON J. M. PROCHECK a program to check the stereochemical quality of protein structures.J. App. Cryst., v. 26, p. 283-291, 1993.

MENG, E.C.; SHOICHET, B.K.; KUNTZ, I.D. Automateddockingwith grid-based energyevaluation.JournalofComputationalChemistry, v.13; p.505-524, 1992.

MELO, F.; FEYTMANS, E. "Novel knowledge-based mean force potential at atomic level".Journal of Molecular Biology. v. 267, p. 207-222, 1997.

NOTREDAME, C.; HIGGINS, D. G.; HERINGA, J. T-Coffee: A novel method for fastandaccuratemultiplesequencealignment. Journalof molecular biology, v. 302, n. 1, p. 205 $217,2000$.

RECK JUNIOR, J.M. et al.SystemicalterationsofbovinehemostasisduetoRhipicephalus (Boophilus) microplusinfestation. Veterinary Science, v. 86, p. 56-62, 2009.

SALENTIN, S. et al. PLIP: fully automated protein-ligand interaction profiler. Nucl.Acids Res. V. 43 p. 443- 447, 2015.

UNIPROT. Disponível em:<http://www.uniprot.org/>. Acesso em 16/03/2018.

ZIAPOUR, et al., Pyrethroid resistance in Iranian field populations of Rhipicephalus

(Boophilus) annulatus, Pesticide Biochemistry and Physiology

http://dx.doi.org/10.1016/j.pestbp.2016.08.001. 